$\begin{array}{lllllllllllllllll}\text { A C T A } & \text { C H E M I C A S C A N D I N A V I C A } & 1 \text { 6 } & \text { (1962) } & 1989-1998\end{array}$

\title{
The Effect of Gamma Radiation on a Number of Water Soluble Vitamins
}

\author{
MONICA S JöSTEDT and L.-E. ERICSON
}

Division of Food Chemistry, Royal Institute of Technology, Stockholm 70, Sweden

\begin{abstract}
Solutions of thiamin hydrochloride, riboflavin, niacinamide, biotin, pteroylglutamic acid and $\mathrm{N}_{5}$-formyltetrahydropteroylglutamic acid have been irradiated with $\gamma$-rays from a ${ }^{60} \mathrm{Co}$-source. Residual activity as well as the formation of biologically active breakdown products was studied using microbiological test systems. No microbial growth factors other than the vitamins themselves were detected in irradiated solutions of thiamin, riboflavin and niacinamide. Biotin-L-sulphoxide was formed on irradiation of biotin and pteroic acid on irradiation of pteroylglutamic acid. A great number of biologically active breakdown fragments were observed in irradiated solutions of $\mathrm{N}_{5}$-formyltetrahydropteroylglutamic acid, amongst them pteroylglutamic acid, $\mathrm{N}_{10}$-formylpteroic acid, pteroic acid and $\mathrm{N}_{10}$-formylpteroylglutamic acid as well as three chemically unidentified growth factors.

It was noted that the degree of destruction as determined spectrophotometrically appeared to be considerably lower than found on microbiological estimation.
\end{abstract}

For the study of the use of irradiation for food preservation, it is of interest 1 to know the effect of ionizing radiation on the nutritive constituents of food. The problem has been examined from different points of view. For example, the stability of vitamins in their natural state has been studied (ct. Refs. ${ }^{1-4}$ ). Model vitamin systems have been investigated with reference to both the physical and chemical effects of ionizing radiation (cf. Refs. ${ }^{5-12}$ ). No efforts have however been made in order to find if biologically active fragments of the vitamins are formed during irradiation. In the experiments described here, the effect of $\gamma$-rays on some B-vitamins - thiamin-hydrochloride, riboflavin, niacinamide, biotin, pteroylglutamic acid and $\mathrm{N}_{5}$-formyltetrahydropteroylglutamic acid - have been studied from this point of view. The pure vitamins were irradiated in buffer solutions. The biological activity after irradiation has been examined microbiologically using cup plate assays and in some cases tube assays. The production of biologically active fragments of some of the vitamins has, moreover, been observed bioautographically. 


\section{EXPERIMENTAL}

Vitamin solutions. Thiamin-hydrochloride, riboflavin and biotin (all three from F. Hoffmann La Roche \& Co, Ltd., Basel, Switzerland) were irradiated at a concentration of $100 \mu \mathrm{g} / \mathrm{ml}$ in $0.01 \mathrm{M}$ acetate buffer having a pH of 5.0. Niacinamide (F. Hoffmann La Roche \& Co, Ltd., Basel, Switzerland) was studied under the same conditions but in phosphate buffer instead of acetate. Pteroylglutamic acid (California Foundation for Biochemical Research, Los Angeles, Cal., USA), $100 \mu \mathrm{g} / \mathrm{ml}$, was dissolved in $0.01 \mathrm{M}$ phosphate buffers of $\mathrm{pH} 6.0,6.5$ and 7.5 while $\mathrm{N}_{5}$-formyltetrahydropteroylglutamic acid ("Leucovorin" Lederle Laboratories Division, American Cyanamid Company, New York, USA), $100 \mu \mathrm{g} / \mathrm{ml}$, was dissolved in pure water and in $0.01 \mathrm{M}$ phosphate buffer of $\mathrm{pH}$. 5.0.

Irradiation. The irradiations were performed using a gamma source ("Hot Pot" with about 3000 Curie ${ }^{60} \mathrm{Co}$ ) at the University of Stockholm. The dose rate was about 0.5 $\mathrm{rad} / \mathrm{h}$. The solutions of thiamin-hydrochloride, riboflavin, biotin and niacinamide were given doses of 10000,100000 and 1000000 rad. Pteroylglutamic acid was irradiated with various doses from 5000 to $500000 \mathrm{rad}$ while $\mathrm{N}_{5}$-formyltetrahydropteroylglutamic acid was subjected to doses from 5000 to 1000000 rad.

Microbiological test systems. The microbiological activity of the various solutions was determined by cup plate and tube assays. The following test organisms were used: For thiamin-hydrochloride and biotin Lactobacillus fermenti ATCC 9338, for riboflavin Lactobacillus casei ATCC 7469, for niacinamide Streptococcus faecalis ATCC 8043, and for folic and folinic acids Streptococcus faecalis ATCC 8043 and Pediococcus cerevisiae (Leuconostoc citrovorum) ATCC 8081.

In the cup plate assays, the plates were prepared as described by Bolinder and Larsen ${ }^{13}$ of this laboratory. For the determination of thiamin, the Bacto Thiamin Assay Medium (Difco) was first tried but did not give satisfactory results. In later assays a basal acetate medium developed by Bolinder ${ }^{13}$ was used. For the cup plate assays of riboflavin, the Bacto Riboflavin Assay Medium (Difco) was used. For the biotin determination the Difco's Bacto Biotin Assay Medium was not satisfactory for the cup plate technique. A modification of the acetate medium gave well-def ined growth zones. The alteration consisted of an addition to the medium of $0.3 \mathrm{ml}$ Tween 80 diluted 200 times. Furthermore, an increment in the turbidity of the bacteria suspension was made from 50 to $25 \%$ transmittance adjusted with a blank of distilled water in a Coleman Model 11 Universal spectrophotometer.

The citrate medium described by Bolinder and Larsen ${ }^{13}$ was used for the niacinamide assay. For the plates with $S$. faecalis for the determination of folic and folinic acids, this citrate medium supplemented with niacin and with folic acid excluded was employed. The basal acetate medium with niacin and ascorbic acid added was used for the plates containing Pediococcus cerevisiae.

Suitable ranges of concentration for the standard solutions used in the different cup plate assays were: For thiamin $0.5-10 \mu \mathrm{g} / \mathrm{ml}$, for riboflavin $0.1-10 \mu \mathrm{g} / \mathrm{ml}$ and for biotin $0.001-0.1 \mu \mathrm{g} / \mathrm{ml}$.

Tube assays were performed on folic and folinic acids in conformity with the method described by Bolinder and Larsen ${ }^{13}$. The same media were used as for the plate assays. The standard solutions pteroylglutamic acid and $\mathrm{N}_{5}$-formyltetrahydropteroylglutamic acid were used in a concentration range of $0.02-2.0 \mu \mathrm{g} / \mathrm{ml}$. The growth was determined by turbidimetric measurements at $640 \mathrm{~m} \mu$ after an incubation period of $24 \mathrm{~h}$ at $37^{\circ} \mathrm{C}$.

Bioautography. The different breakdown fragments formed upon irradiation were separated by paper chromatography on Whatman No. 1 filter paper using the descending technique. The thiamin chromatograms were run in a solvent system of sec. butanol:water:acetic acid $(75: 28: 1 \mathrm{v} / \mathrm{v})$ for $18 \mathrm{~h}$ and with unirradiated thiamin-hydrochloride as a standard spot. The same solvent system was used for riboflavin and biotin. The riboflavin chromatogram was run for $18 \mathrm{~h}$ and had riboflavin as standard. Biotin was chromatographed for $51 / 2 \mathrm{~h}$ and biotin and biotin-L-sulphoxide were used as reference substances. For the chromatography of niacinamide, isopropanol:water $(77: 23 \mathrm{v} / \mathrm{v})$ was used and, as standard spots, niacin and niacinamide were employed. The chromatogram was run for $16 \mathrm{~h}$. The solvent system for folic and folinic acids was sec. butanol:water:acetic acid $(75: 24: 1 \mathrm{v} / \mathrm{v})$. The papers were run for $18 \mathrm{~h}$. Pteroylglutamic acid, $\mathrm{N}_{5}$-formyltetrahyd-

Acta Chem. Scand. 16 (1962) No. 8 
ropteroylglutamic acid, pteroic acid, $\mathrm{N}_{10}$-formylpteroic acid and $\mathrm{N}_{10}$-formylpteroylglutamic acid were used as standards.

The chromatograms were dried at room temperature and then placed on agar plates containing the appropriate test medium and test organism. The test organisms used for seeding the plates were grown overnight in the Bacto Micro Inoculum Broth (Difco) supplemented as described by Bolinder and Larsen ${ }^{13}$. The cells were harvested by centrifugation, washed twice and suspended in saline to give a suitable transmittance reading. This was for the thiamin, riboflavin and niacinamide plates $50 \%$, for the biotin $25 \%$, for the folic and folinic acids $S$. faecalis plates $50 \%$ and for the P.cerevisiae plates $70 \%$. Of such a suspension, $5 \mathrm{ml}$ was taken for $150 \mathrm{ml}$ agar medium.

Synthesis of biotin-L-sulphoxide. The biotin-L-sulphoxide, used as a standard on the biotin chromatograms, was synthesized according to Melville ${ }^{14}$.

Spectra. The absorption spectra of unirradiated and irradiated pteroylglutamic and $\mathrm{N}_{5}$-formyltetrahydropteroylglutamic acids were measured in a Beckman Model DU spectrophotometer. The concentration of the standard solutions was $10 \mu \mathrm{g} / \mathrm{ml}$. The irradiated solutions were diluted ten times before measurement.

\section{RESULTS AND DISCUSSION}

The sensitivity of thiamin hydrochloride to ionizing radiation has been confirmed by several investigators ${ }^{1,3,5}$. In our tests thiamin hydrochloride was partly destroyed by doses of 10000 and $100000 \mathrm{rad}$ as shown by the cup plate assay results presented in Table 1 . In the bioautography test, the two solutions brought about the growth of the bacteria in zones having the same $R_{F}$ value as standard thiamin hydrochloride. No biologically active fragments formed by the $\gamma$-rays were therefore indicated in this test. The solution irradiated with 1 Mrad did not give any growth in the cup plate assay. Nor did it stimulate the growth of the bacteria in the bioautography when $10 \mu \mathrm{l}$ of the solution was applied to the chromatogram. The mechanism for the destruction of thiamin hydrochloride exposed to ionizing radiation is not known. Gregorlin et al. ${ }^{15}$ have shown that, when diphosphothiamin was irradiated with $\gamma$-rays, thiochrome and oxythiamin were found among the breakdown products. These substances might have been formed also in our experiments but would not have been detected by our test methods.

The cup plate assay of irradiated riboflavin showed, as would be expected, that the extent of the destruction increased with increasing doses of radiation. The results are presented in Table 1. In the bioautography test, all

Table 1. Effect of $\gamma$-rays on thiamin, riboflavin and biotin.

\begin{tabular}{|l|c|c|c|}
\hline \multirow{2}{*}{ Vitamin } & \multicolumn{3}{|c|}{ Residual microbiological activity in \% at the doses } \\
\cline { 2 - 4 } & $10000 \mathrm{rad}$ & $100000 \mathrm{rad}$ & $1000000 \mathrm{rad}$ \\
\hline Thiamin & 98 & 65 & 0 \\
Riboflavin & 98 & 58 & 2 \\
Biotin & 96 & 33 & 0.2 \\
\hline
\end{tabular}

Acta Chem. Scand. 16 (1962) No. 8 


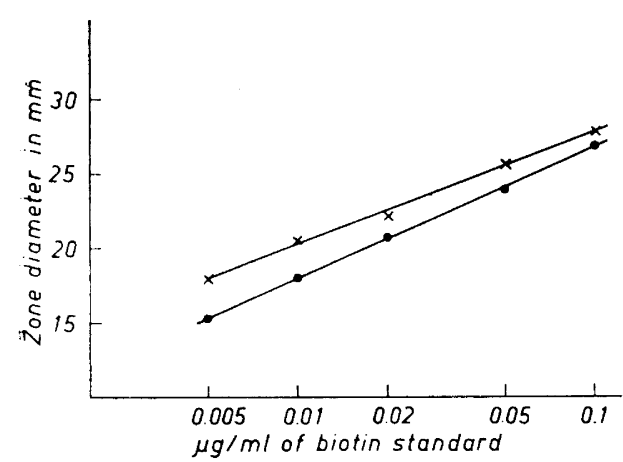

Fig. 1. Growth response of $L$. fermenti in the cup plate assay to various concentrations of non-irradiated biotin $(x)$ and to dilutions of biotin irradiated with $1 \mathrm{Mrad}$ (O). The highest concentration used of the irradiated solution was obtained by diluting the original solution containing $100 \mu \mathrm{g}$ biotin $/ \mathrm{ml} \mathrm{1:3.3.}$
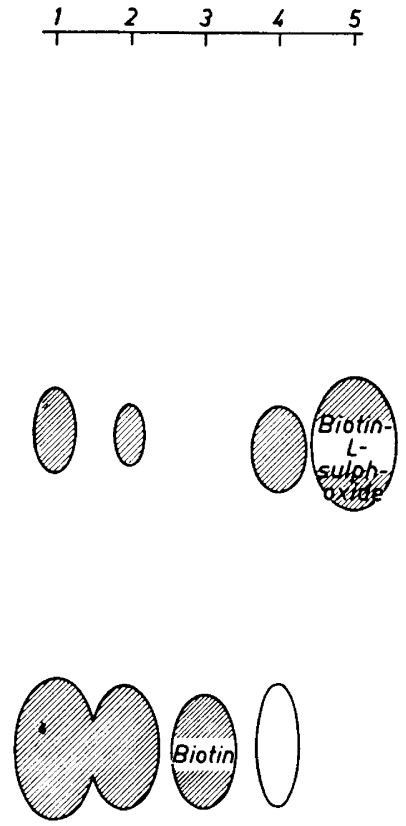

Fig. 2. Bioautography with $L$. fermenti of the following solutions:

1. $1 \mu \mathrm{l}$ of a biotin solution $(100 \mu \mathrm{g} / \mathrm{ml})$ irradiated with 10000 rad, diluted 1:100.

2. $1 \mu \mathrm{l}$ of the biotin solution irradiated with $100000 \mathrm{rad}$, diluted 1:50.

3. $1 \mu \mathrm{l}$ of a standard solution containing $0.5 \mu \mathrm{g} / \mathrm{ml}$ of biotin.

4. $3 \mu \mathrm{l}$ of the biotin solution irradiated with 1 Mrad, undiluted.

5. Biotin-I,-sulphoxide.

three irradiated solutions gave growth only in zones corresponding to standard riboflavin. The chemical effects of the ionizing radiation on riboflavin are not quite unravelled. According to Goldblith et al. ${ }^{8}$, Iumichrome may be formed. Guldener ${ }^{12}$ has found that the ionizing radiation leads to the formation of isoalloxazin. Neither of these substances has a growth promoting effect on $L$. case $i$ and they have therefore not been observed in our experiments.

In the bioautography test on irradiated niacinamide, only growth zones with the same $R_{F}$ value as the niacinamide standard were indicated. Neither niacin nor other biologically active fragments were formed during the irradiation. This shows that the $\mathrm{CO}-\mathrm{NH}_{2}$ bond in the niacinamide is relatively stable towards ionizing radiation.

The cup plate assays of irradiated biotin solutions showed that the effect of $\gamma$-rays on biotin was in accordance with the effect on the vitamins described 


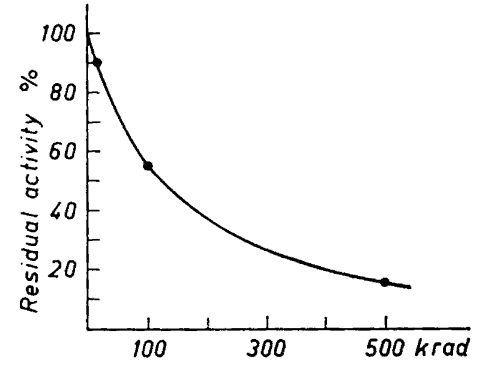

Fig. 3. Residual microbiological activity in solutions of pteroylglutamic acid (100 $\mu \mathrm{g} / \mathrm{ml}$ ) irradiated in phosphate buffer of $\mathrm{pH}$ 7.5. The values are calculated from a tube assay with $S$. faecalis.

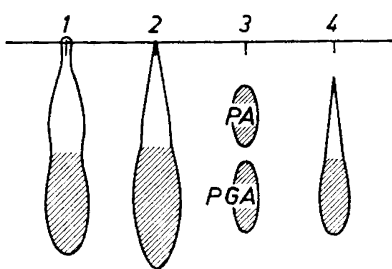

(B)
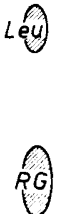

Fig. 4. Bioautography with $S$. faecalis of pteroylglutamic acid irradiated in phosphate buffer of $\mathrm{pH} 6.5$ :

1. $1 \mu \mathrm{l}$ of a solution $(100 \mu \mathrm{g} / \mathrm{ml})$ irradiated with 10000 rad, diluted 1:10.

2. $1 \mu 1$ of the solution irradiated with $100000 \mathrm{rad}$, diluted 1:10.

3. $1 \mu \mathrm{l}$ of the following standard solutions: Pteroic acid (PA) $1 \mu \mathrm{g} / \mathrm{ml}$, pteroylglutamic acid (PGA) $0.2 \mu \mathrm{g} / \mathrm{ml}, \mathrm{N}_{10}$-formylpteroic acid (R) $0.2 \mu \mathrm{g} / \mathrm{ml}, \mathrm{N}_{5}$-formyltetrahydropteroylglutamic acid (Leu) $0.2 \mu \mathrm{g} / \mathrm{ml}$ and $\mathrm{N}_{10}$-formylpteroylglutamic acid (RG) $0.2 \mu \mathrm{g} / \mathrm{ml}$.

4. $1 \mu \mathrm{l}$ of the solution irradiated with $500000 \mathrm{rad}$, diluted 1:10.

earlier. The microbiological activity of the solutions decreased the higher the doses which the solutions were subjected to. This is shown in Table 1. As can be seen in Fig. 1, the slope of the line representing growth diameter versus concentration was different for the biotin solution irradiated with 1 Mrad as compared to that for the non-irradiated biotin. This suggested that there might have been microbiologically active fragment(s) formed during the irradiation. The bioautography test verified this assumption because two different growth zones were obtained on the agar plate. This is shown in Fig. 2. One of the growth zones had an $R_{F}$ value corresponding to biotin. The other growth factor was compared with earlier known biotin-active factors for $L$. fermenti. Biotin-I-sulphoxide was the most probable of these since its $R_{F}$ value was the same as that of our unknown substance. We therefore synthesized biotin-I-sulphoxide and compared its chromatographic and microbiological properties with those of the unknown factor which confirmed 


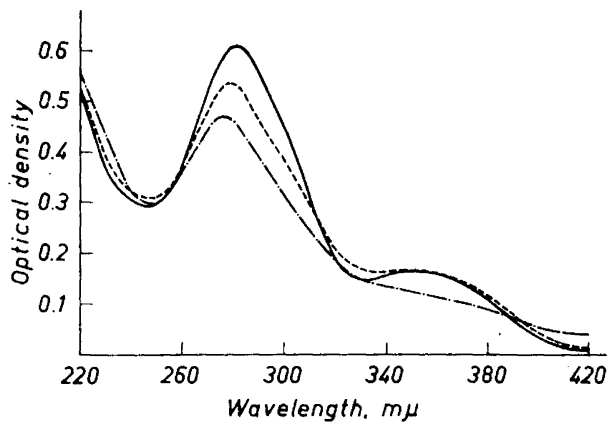

Fig. 5. Light absorption spectra for a solution of non-irradiated pteroylglutamic acid $10 \mu \mathrm{g} / \mathrm{ml} \mathrm{(-.)} \mathrm{and} \mathrm{for} \mathrm{pteroylglutamic}$ acid solutions $(100 \mu \mathrm{g} / \mathrm{ml})$ irradiated with $100000 \mathrm{rad}\left({ }_{-}-\right)$and $500000 \mathrm{rad}$ (-...-). The pteroylglutamic acid was dissolved in phosphate buffer of $\mathrm{pH} 7.5$. The irradiated solutions were diluted ten times before measurement.

our presumptions, as can be seen in Fig. 2. As far as the authors know, this is the first published report on the effect of $\gamma$-rays on biotin and it is therefore not possible to compare our results with those of other research workers.

The loss of pteroylglutamic acid was determined by a tube assay with $S$. faecalis. Residual microbiological activity as a function of radiation dose is shown in Fig. 3. Dilutions of the irradiated pteroylglutamic acid solutions gave curves which closely followed the standard curve and thus did not suggest the presence of any biologically active factor in the irradiated solutions other than pteroylglutamic acid. However the bioautography test with $S$. faecalis indicated that at least one microbiologically active fragment was formed when the solution was subjected to $\gamma$-rays, especially at the lower dose levels. This can be seen in Fig. 4 where a growth zone with the same $R_{F}$ value as pteroic acid appears. An identical chromatogram was also placed on an agar plate containing $P$. cerevisiae. No growth factor for this microorganism could be detected in $\gamma$-irradiated solutions of pteroylglutamic acid. The light absorption spectra, Fig. 5, showed that the irradiation caused a moderate decrease in the pteroylglutamic acid peak at $282 \mathrm{~m} \mu$. A tendency for the absorption peak to move towards shorter wavelengths was also noticed. The solution given a dose of $500000 \mathrm{rad}$ gave furthermore a somewhat lower curve between the wavelengths 330 and $390 \mathrm{~m} \mu$. Since this absorption maximum is considered to be caused by the pteridin part of the molecule, this observation is in accordance with the fact that the proportion of pteroic acid seemed to decrease in the irradiated solutions at higher doses (Fig. 4). However,

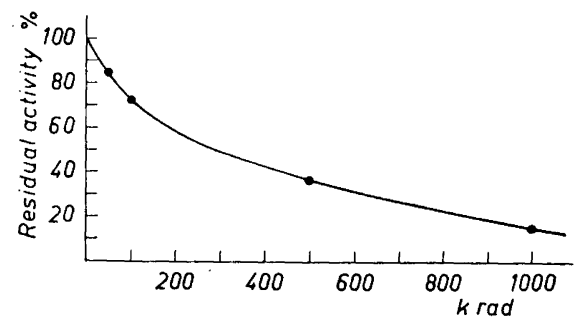

Fig. 6. Residual microbiological activity in solutions of Leucovorin $(100 \mu \mathrm{g} / \mathrm{ml})$ irradiated in phosphate buffer of $\mathrm{pH}$ 5.0. The values are calculated from a tube assay
with $S$. faecalis. 


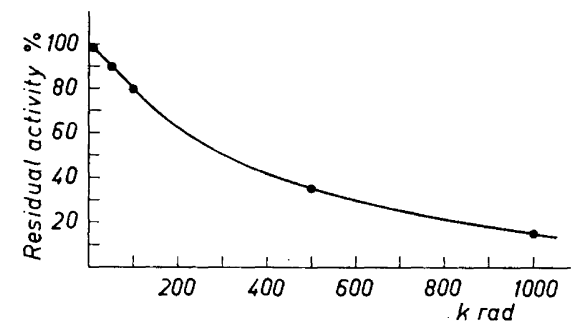

Fig. \%. Residual microbiological activity in solutions of Leucovorin $(100 \mu \mathrm{g} / \mathrm{ml})$ irradiated in phosphate buffer of $\mathrm{pH}$ 5.0. The values are calculated from a tube assay with $P$. cerevisiae.

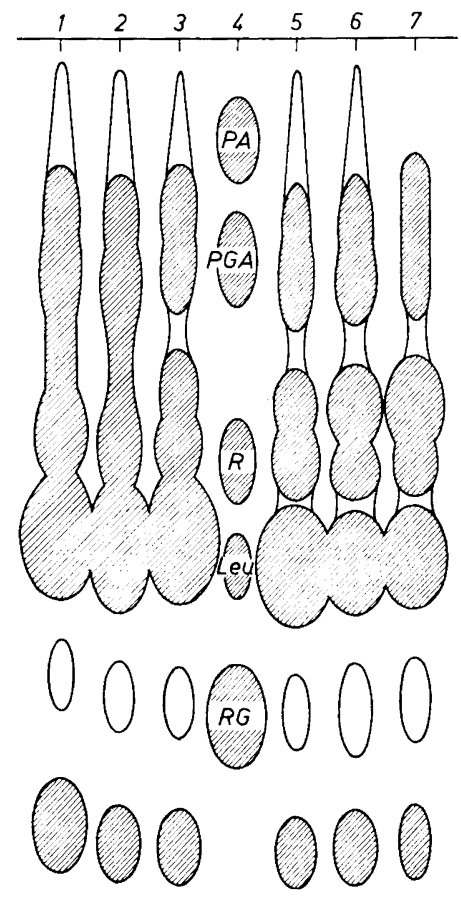

Fig. 8. Bioautography with $S$. faecalis of Leucovorin irradiated in phosphate buffer of $\mathrm{pH}$ 5.0. The solutions tested were:

1. $1 \mu \mathrm{l}$ of a solution $(100 \mu \mathrm{g} / \mathrm{ml})$ irradiated with 5000 rad, diluted 1:5.

2. $1 \mu \mathrm{l}$ of the solution irradiated with $10000 \mathrm{rad}$, diluted 1:5.

3. $1 \mu \mathrm{l}$ of the solution irradiated with 50000 rad, diluted 1:5.

4. $1 \mu \mathrm{l}$ of the following standard solutions: Pteroic acid (PA) $1 \mu \mathrm{g} / \mathrm{ml}$, pteroylglutamic acid (PGA) $0.2 \mu \mathrm{g} / \mathrm{ml}, \mathrm{N}_{10}$-formylpteroic acid (R) $0.2 \mu \mathrm{g} / \mathrm{ml}, \mathrm{N}_{5}$-formyltetrahydroglutamic acid (Leu) $0.2 \mu \mathrm{g} / \mathrm{ml}$ and $\mathrm{N}_{10}$-formylpteroylglutamic acid (RG) $0.2 \mu \mathrm{g} / \mathrm{ml}$.

5. $1 \mu \mathrm{l}$ of the solution irradiated with $100000 \mathrm{rad}$, diluted 1:5.

6. $1 \mu \mathrm{l}$ of the solution irradiated with 500000 rad, diluted 1:3.3.

7. I $\mu \mathrm{l}$ of the solution irradiated with 1 Mrad, diluted 1:2.5.

Okada et al. ${ }^{10}$ did not observe any destruction of pteridines in corresponding experiments.

No effects due to the $\mathrm{pH}$ variations in the buffer solution used could be observed either in spectrophotometrical or microbiological tests. In a separate

Acta Chem. Scand. 16 (1962) No. 8 


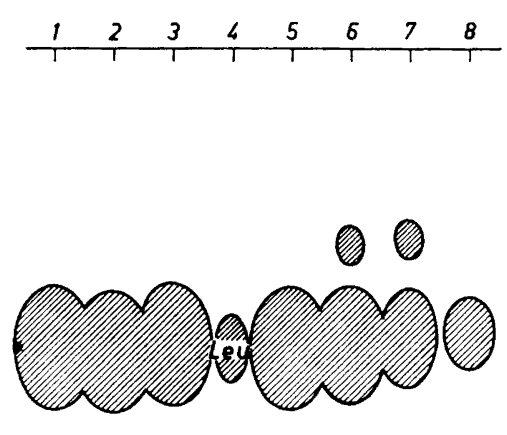

Fig. 9. Bioautography with $P$. cerevisiae of Leucovorin irradiated in phosphate buffer of $\mathrm{pH}$ 5.0. The solutions tested were: 1. $1 \mu \mathrm{l}$ of a solution $(100 \mu \mathrm{g} / \mathrm{ml})$ irradiated with 5000 rad, diluted 1:10.

2. $1 \mu$ l of the solution irradiated with 10000 rad, diluted 1:10.

3. $1 \mu \mathrm{l}$ of the solution irradiated with 50000 rad, diluted 1:10.

4. $1 \mu \mathrm{l}$ of the following standard solutions: Pteroic acid $1 \mu \mathrm{g} / \mathrm{ml}$, pteroylglutamic acid $0.2 \mu \mathrm{g} / \mathrm{ml}, \mathrm{N}_{10}$-formylpteroic acid $0.2 \mu \mathrm{g} / \mathrm{ml}, \mathrm{N}_{5}$-formyltetrahydropteroylglutamic acid (Leu) $0.2 \mu \mathrm{g} / \mathrm{ml}$ and $\mathrm{N}_{10}$. formylpteroylglutamic acid $0.2 \mu \mathrm{g} / \mathrm{ml}$.

5. $1 \mu \mathrm{l}$ of the solution irradiated with 100000 rad, diluted 1:10.

6. $1 \mu \mathrm{l}$ of the solution irradiated with 500000 rad, diluted 1:10.

7. $1 \mu \mathrm{l}$ of the solution irradiated with 1 Mrad, diluted 1:10.

8. $1 \mu \mathrm{l}$ of unirradiated Leucovorin $1 \mu \mathrm{g} / \mathrm{ml}$.

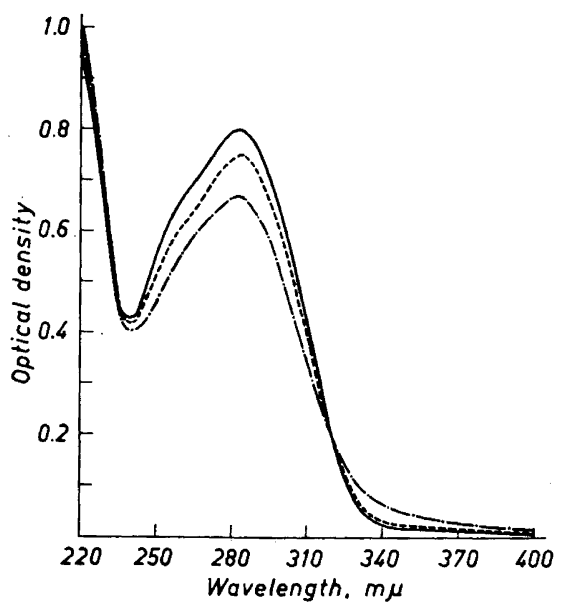

Fig. 10. Light absorption spectra for a solution of non-irradiated Leucovorin 10 $\mu \mathrm{g} / \mathrm{ml}(-)$ ) and for Leucovorin solu. tions $(100 \mu \mathrm{g} / \mathrm{ml})$ irradiated in phosphate buffer of pH 5.0 with $100000 \mathrm{rad}(\ldots)$ and $500000 \mathrm{rad}(\ldots+.-)$. The irradiated solutions were diluted $1: 10$ before measurement.

experiment the pteroylglutamic acid solution was deaerated and $10 \mathrm{mg}$ ascorbic acid $/ \mathrm{ml}$ was added just before irradiation with $100000 \mathrm{rad}$. The pteroylglutamic acid was then totally protected.

It might be supposed that the decrease in the pteroylglutamic acid peak at $282 \mathrm{~m} \mu$ in the spectra should be a direct measure of the decrease in the amount of pteroylglutamic acid. That this is not the case is evident from the microbiological tests. These have given much lower values in spite of the fact that the solutions contain, besides pteroylglutamic acid, at least one other microbiologically active fragment. Okada et al. ${ }^{10}$ have used the results from a polarographic test to calculate the amount of pteroylglutamic acid remaining after irradiation. The values obtained were also much higher than our micro- 
biological data. It therefore seems to be inadequate to use physico-chemical measurements in order to obtain correct values for the vitamin destruction due to ionizing radiation. Probably there are substances formed during the irradiation which are chemically closely related to pteroylglutamic acid and are thus sensitive to this type of analysis but which lack biological activity. Since the main interest in the study of the effects of ionizing radiation on vitamins consists of the biological aspects, it is clear that biological tests should be performed.

The irradiated solutions of Leucovorin were tested by tube assays both with $S$. faecalis and $P$. cerevisiae. From these tests, residual microbiological activity relative to dose level was calculated. The results are presented in Figs. 6 and 7. Dilutions of the irradiated Leucovorin solutions gave curves that closely followed the standard curve. Therefore the tube assays did not suggest that any new microbiologically active fragments were formed during the irradiations. However, the bioautography test, especially with $S$. faecalis, clearly demonstrated that a number of new growth factors was formed. Fig. 8 gives a picture of such a bioautogram. It can be seen that the following degradation products could be identified: pteroylglutamic acid, $\mathrm{N}_{10}$-formylpteroic acid, pteroic acid and $\mathrm{N}_{10}$-formylpteroylglutamic acid. Only small quantities of the last two compounds were formed. Some unknown factors can also be observed. One of these is situated quite near pteroylglutamic acid, another just above $\mathrm{N}_{10}$-formylpteroic acid. The growth zone at the very bottom might be caused by a factor identical to Factor I described by Ericson ${ }^{16}$.

In Fig. 9, a $P$. cerevisiae plate is reproduced. Besides $\mathrm{N}_{5}$-formyltetrahydropteroylglutamic acid, there is a new growth promoting factor, probably the same as that which appeared on the $S$. faecalis plate just above $\mathrm{N}_{10}$-formylpteroic acid. After keeping the solutions at $-20^{\circ} \mathrm{C}$ for two months, they were then re-chromatographed. A new growth zone with an $R_{F}$-value lower than pteroic acid was found on both $S$. faecalis and $P$. cerevisiae plates. No differences could be noticed between Leucovorin solutions irradiated in water and in phosphate buffer.

The light absorption spectra for unirradiated and irradiated Leucovorin are shown in Fig. 10. The irradiated solutions have lower peaks, at the wavelength $282 \mathrm{~m} \mu$, than $\mathrm{N}_{5}$-formyltetrahydropteroylglutamic acid and a somewhat greater absorption between 320 and $400 \mathrm{~m} \mu$. As could be noticed for pteroylglutamic acid, the decrease in the peak at $282 \mathrm{~m} \mu$ is no measure of the destruction of the vitamin. The results from the Leucovorin experiments thus confirm the view that biological tests must be performed when the decrease in vitamin activity after irradiation is to be investigated.

The authors would like to acknowledge research grants from the Swedish Technical Research Council and the Swedish Natural Science Research Council.

\section{REFERENCES}

1. Alexander, H. D., Day, E. J., Sauberlich, H. E. and Salmon, W. D. Federation Proc. 15 (1956) 921.

2. Day, E. J., Alexander, H. D., Sauberlich, H. E. and Salmon, W. D. J. Nutrition 62 (1957) 27.

Acta Chem. Scand. 16 (1962) No. 8 
3. Day, E. J., Sauberlich, H. E., Alexander, H. D. and Salmon, W. D. J. Nutrition 62 (1957) 107.

4. Ziporin, Z. Z., Kraybill, H. F. and Thach, H. J. J. Nutrition 63 (1957) 201.

5. Dunlap, C. E. and Robbins, F. C. Am. J. Roentgenol. Radium Therapy 50 (1943) 641.

6. Proctor, B. E. and Goldblith, S. A. Nucleonics 3 (1948) 32.

7. Goldblith, S. A., Proctor, B. E., Hogness, J. R. and Langham, W. H. J. Biol. Chem. 179 (1949) 1163.

8. Goldblith, S. A. and Proctor, B. E. Nucleonics 5 (1949) 50.

9. Proctor, B. E. and Goldblith, S. A. Nucleonics 5 (1949) 56.

10. Okada, I., Hirano, T., Kikuchi, T. and Doguchi, M. J. Tokyo Univ. Fisheries 44 (1958) 39.

11. Ueno, Y. Radioisotopes (Tokyo) 8 (1959) 253.

12. Guldener, P. Die Wirkung ionisierender Strahlungen auf Riboflavin (Diss.) Bern 1960.

13. Bolinder, A. E. and Larsen, B. Acta Chem. Scand. 15 (1961) 823.

14. Melville, D. B. J. Biol. Chem. 208 (1954) 495.

15. Gregolin, C., Rossi, C. S. and Siliprandi, N. Radiation Research 13 (1960) 185.

16. Ericson, L.-E. Arkiv Kemi 6 (1953) 503.

Received May 10, 1962. 